\title{
Response to an intervening event reverses nonspatial repetition effects in 2 AFC tasks: Nonspatial IOR?
}

\author{
Adam Spadaro • Chao He • Bruce Milliken
}

Published online: 8 December 2011

(C) Psychonomic Society, Inc. 2011

\begin{abstract}
The repetition effect in two-alternatiave forced choice (2AFC) tasks is a cornerstone effect in human cognition. Yet the experiments described here show that the customary benefit of repetition reverses to a cost of repetition when participants respond to an irrelevant event between targets. In Experiments $1 \mathrm{~A}-1 \mathrm{C}$, participants made manual $2 \mathrm{AFC}$ decisions to both of two consecutive targets on a trial and, on some trials, also made a manual response to an intervening event that appeared between the two targets. A repetition benefit was observed when no intervening event appeared, whereas a repetition cost was observed when a response was required to an intervening event. Experiment 2 ruled out a solely strategic interpretation of the repetition cost effect observed on intervening event trials. In Experiments $3 \mathrm{~A}$ and $3 \mathrm{~B}$, an intervening event that required a simple vocal "go" response also produced a repetition cost. In Experiment 4, a repetition cost was observed when the intervening event was changed to a tone presented aurally. In Experiment 5, the repetition benefit was observed when a response was withheld to an intervening event. A dual-process interpretation of these results is discussed, with one process related to episodic integration, and the other related to processes that produce inhibition of return.
\end{abstract}

Keywords Attention · Inhibition of return · Priming

A. Spadaro $(\square) \cdot$ C. He $\cdot$ B. Milliken

Department of Psychology, Neuroscience, and Behaviour,

McMaster University,

Hamilton, Ontario L8S4K1, Canada

e-mail: spadaraj@mcmaster.ca

\section{Introduction}

Cognitive psychologists measure performance in carefully designed tasks, with the idea that these measures tell us something useful about basic cognitive processes. If experimental tasks mapped neatly, in a one-to-one relation, onto specific cognitive processes, our job would be relatively simple. Yet tasks often measure more than one cognitive process, and worse still, varying a task parameter can result in an effect on more than one of those processes. Although problems associated with the lack of process purity of tasks have taken on a high profile in the memory literature (Jacoby, 1991), they may be equally problematic in other research domains. In this article, we focus on this potential problem in the attention and performance domain and, in particular, in studies that measure trial-to-trial repetition effects.

The general point made in this article is that an assumption of process purity with respect to a very simple task, that used to measure repetition effects in two-alternative forced choice (2AFC) tasks, may have obscured the fact that inhibition of return (IOR; Posner \& Cohen, 1984) can be measured in both spatial and nonspatial tasks. We report a series of experiments that required participants to make $2 \mathrm{AFC}$ decisions to nonspatial properties (e.g., color, size, identity) of targets on all trials. The key result reported here is that under conventional testing conditions, we observed faster responses for repetitions than for nonrepetitions, as might be expected. Yet when participants were forced to respond to an event intervening between prime and target, we observed the opposite effect - that is, slower responses for repetitions than for nonrepetitions. This result suggests that more than a single process underlies repetition effects in 2AFC tasks and that one of these processes may be similar to that which underlies IOR (Posner \& Cohen, 1984) in tasks that measure spatial repetition effects. 
To set the context for the empirical work reported here, the remainder of the introduction addresses the following three issues. First, we describe the spatial IOR effect and discuss briefly how it is interpreted. Second, we review briefly the literature that has addressed whether IOR-like effects can occur outside the domain of spatial-orienting studies. Finally, we introduce our research strategy, in which we measure repetition effects in simple $2 \mathrm{AFC}$ tasks that require a response to targets on all trials. The key variable that we manipulate in these experiments is the presence or absence of a requirement to respond to an intervening event between consecutive targets. As was mentioned above, the result of note is that repetition priming is observed without an intervening event, while the opposite result is observed when participants are required to respond to an intervening event.

\section{Spatial inhibition of return}

A spatial-cuing method using nonpredictive peripheral cues is typically used to measure the IOR effect. This method involves presenting an abrupt onset cue at one of two or more spatial locations, and then, after some time has elapsed, a target appears at either the cued peripheral location or some other location (Posner \& Cohen, 1984; for useful reviews, see Klein, 2000; Lupiáñez, Klein, \& Bartolomeo, 2006; Taylor \& Klein, 1998b). The relative proportions of cued and uncued trials are set so that the cue does not provide predictive information about the location of the following target, thus allowing the inference that cuing effects tap into reflexive orienting processes, rather than strategic orienting processes. When the time between onset of cue and target is relatively short—say, less than about $300 \mathrm{~ms}$ - responses to detect, localize, or identify the target are typically faster for cued than for uncued trials. In contrast, when the time between onset of cue and target is longer than about $300 \mathrm{~ms}$, responses are typically slower for cued than for uncued trials (for more detailed discussions of time course issues, see also Lupiáñez, Milán, Tornay, Madrid, \& Tudela, 1997; Samuel \& Kat, 2003). This effect was labeled inhibition of return to reflect the idea that attention may initially be captured by the abrupt onset cue but then inhibited from returning to that location after it has been disengaged and reoriented to the central fixation location. Following many other researchers, we use the acronym IOR to refer to this effect throughout this article.

In large part, the term IOR has come to take on meaning that is tied quite specifically to shifts of attention in space. The underlying assumption is that attention acts as a "spotlight" that shifts from location to location in the visual field and that objects subject to the beam of this spotlight are processed with greater efficiency than are objects in regions lying outside of the beam (Posner, 1980). By this view, IOR effects occur because attention is inhibited from shifting back to locations or objects that have already been attended. This theoretical account has appeal in terms of adaptive utility, in that search of a visual environment would be inefficient if attention reoriented continuously to locations that have already been searched (Klein, 1988). Instead, an attentional bias that favors novel locations would support more efficient coverage of the search space. This proposed link between IOR and spatial orienting is broadly consistent with an oculomotor hypothesis offered by Rafal, Calabresi, Brennan, and Sciolto (1989), in which they suggested that IOR may be directly related to activation of the oculomotor system that accompanies the programming of eye movements (but see Chica, Klein, Rafal, \& Hopfinger, 2010).

In addition to empirical links to oculomotor control, the idea that IOR reflects a dedicated spatial-orienting mechanism stems, at least in part, from the assumption that repetition of nonspatial stimulus dimensions (e.g., color, form) results in repetition priming rather than IOR. Indeed, there are plenty of studies in the literature that have demonstrated benefits rather than costs of stimulus repetition (Bertelson, 1961; Kirby, 1976; Kornblum, 1973; Maljcovic \& Nakayama, 1994; Rabbitt, 1968), to the point that repetition priming is a cornerstone construct in most introductory courses in human cognition. Nonetheless, a small number of studies have examined whether, when tested under conditions like those used in studies of spatial orienting, repetition of nonspatial dimensions might produce an IOR-like result, rather than repetition priming. A brief review of these studies follows.

\section{Nonspatial inhibition of return?}

Although most research conducted on IOR rests on the assumption that it reflects a process dedicated to the control of spatial orienting, a small number of studies have examined whether a similar effect occurs with nonspatial stimuli. For example, Kwak and Egeth (1992) presented stimuli to the left or right of central fixation, and the participants' task was simply to detect the onset of target stimuli on all trials, much as in prior studies of IOR. Importantly, the stimuli on consecutive trials matched or mismatched not just in location, but also in color. It had previously been shown that IOR for repeated locations occurs even when participants make a response to all targets in a series of trials (i.e., a target-target procedure), and not only when participants withhold a response to a cue and then respond to a following target (i.e., a cue-target procedure; Maylor \& Hockey, 1985). In accord with this prior research, Kwak and Egeth observed slower responses to targets that appeared in the same location as an immediately preceding target than to targets that appeared in the location opposite the immediately preceding target. At the same time, responses were 
faster for targets that matched in color than for targets that mismatched in color with the immediately preceding target. In others words, these researchers observed an IOR effect with respect to spatial location together with a facilitation effect for color, suggesting that IOR indeed may be limited to conditions that measure the control of spatial orienting (see also Fox \& de Fockert, 2001; Tanaka \& Shimojo, 1996; Taylor \& Donnelly, 2002).

However, Law, Pratt, and Abrams (1995) noted that attention might not have been disengaged effectively from the target color from one trial to the next in the Kwak and Egeth (1992) study. They addressed this issue by using a task that required detection of a target following presentation of a cue that either matched or mismatched the target in color. All cues and targets were squares presented centrally, and importantly, a neutral color square that matched neither the cue nor the target was presented at a temporal position between the cue and target. The rationale for the use of this neutral stimulus was that it ought to disengage attention from the color of the preceding cue, and if IOR requires disengagement of attention from the cue, an IOR-like effect for color repetition might well occur here where it failed to occur in the study by Kwak and Egeth. The results were in accord with this prediction; responses were slower for targets that matched the color of the preceding cue, and this IOR-like effect was observed only when a neutral distractor was presented between the cue and target.

Taylor and Klein (1998a) examined whether the colorbased effect reported by Law et al. (1995) follows the same time course as spatial IOR. In particular, in studies of spatial orienting, one often observes facilitation for short cue-target stimulus onset asynchronies (SOAs) that gives way to IOR at longer cue-target SOAs. In contrast, Taylor and Klein (1998a) found that Law et al.'s color-based repetition cost was insensitive to cue-target SOA and, therefore, concluded that it was not caused by the same mechanism as spatial IOR (see also Fox \& de Fockert, 2001, for a similar interpretation). Although this specific conclusion can be debated (Francis \& Milliken, 2003; see also the General Discussion section), perhaps the more important point raised by Taylor and Klein (1998a) is a general one, that nonspatial repetition costs in performance may or may not be caused by the same process that underlies spatial IOR effects.

Following on this theme, our concern here is how one might go about evaluating whether the same or different processes underlie spatial IOR effects and nonspatial repetition effects. One straightforward approach would be to measure spatial and nonspatial repetition effects under comparable conditions (e.g., Kwak \& Egeth, 1992) and then to compare whether the effects are qualitatively similar, or qualitatively different. However, even if spatial and nonspatial repetition effects appear to be qualitatively different, there is no guarantee that each of the effects measures one and only one process and, therefore, also no guarantee that the processes underlying the two effects are qualitatively different. A concrete description of this problem in the present research context may make this issue more transparent.

Consider one of the simplest methods for measuring repetition effects, the $2 \mathrm{AFC}$ task. Here, participants are asked to hit one of two response keys for either of two possible targets on each trial. In a task that required participants to identify target letters on each trial, Bertelson (1961) noted long ago that responses to repeated targets were faster than those to alternating targets, and related results have since been reported by many researchers in a variety of tasks (Campana \& Casco, 2009; Hillstrom, 2000; Huang, Holcombe, \& Pashler, 2004; Kristjánsson \& Campana, 2010; Maljcovic \& Nakayama, 1994). Yet it has also long been known that when participants are required to locate target stimuli on each trial of a 2 AFC task, responses are typically slower for repeated targets than for alternating targets; in other words, an IOR effect is observed (Maylor \& Hockey, 1985). Given these qualitatively different effects of repetition for nonspatial and spatial stimulus dimensions, it is tempting to conclude that the process that underlies IOR in the spatial 2AFC task plays no role in determining the repetition effect in the nonspatial $2 \mathrm{AFC}$ task.

However, this conclusion follows logically only if the repetition effects measured in the two tasks are determined by one and only one process. If this assumption were incorrect, some form of process analysis would be necessary to determine whether the process underlying spatial IOR effects might also contribute to nonspatial repetition effects. In particular, the nonspatial repetition effect could be due to the joint contribution of two processes: one that speeds responses for repetitions, relative to alternations, and another that slows responses for repetitions, relative to alternations, with the sign of the repetition effect ultimately determined by the relative strength of these two processes. Indeed, a similar dual-process framework has been offered within the spatialorienting literature to explain the time course of IOR (Klein, 2000), a framework that also fits some compelling spatialorienting data gathered from split-brain patients (Tipper et al., 1997).

\section{The present study}

Following the dual-process logic described above, in the present set of experiments, we asked whether a nonspatial 2AFC task might reveal an IOR-like cost of repetition under testing conditions designed to disrupt the process responsible for repetition benefits. To address this issue, we followed a precedent set in prior studies showing that an event intervening between cue and target is sometimes necessary to observe IOR-like effects in studies of nonspatial orienting 
(Fox \& de Fockert, 2001; Law et al., 1995). However, we surmised that the mere presentation of a "neutral" intervening event might not be sufficient to entirely disrupt the process responsible for repetition benefits in nonspatial 2AFC tasks. In particular, we assume that processes that allow participants to respond to trial $n$ by retrieving a stimulus-response (S-R) episode of trial $n$-1 play an important role in producing repetition benefits in nonspatial $2 \mathrm{AFC}$ tasks (Hommel, 1998; Logan, 1988; Pashler \& Baylis, 1991; Rabbitt, 1968). Given that disruption of this type of event integration process was the goal, the starting point for our study was to evaluate the influence of requiring participants to attend and respond to a "neutral" event that intervened between two targets in a nonspatial 2AFC task.

As such, the procedure in the experiments reported here was straightforward. Participants were required to respond by identifying a nonspatial property of a target stimulus presented centrally for two consecutive displays on each trial. On half of the trials, the target stimuli were identical in consecutive displays, while on the other half of the trials, the targets were different. In addition, we manipulated whether an intervening event did or did not occur between presentations of the two consecutive targets. Following Bertelson (1961) and many other researchers, when no intervening event occurred between consecutive targets, we expected faster responses when the targets were identical than when they were different; that is, a repetition priming effect ought to be observed. The more critical issue was whether the requirement to attend and respond to an intervening event between consecutive targets would alter this pattern of results. In particular, we were interested in whether response to a task-irrelevant intervening event would disrupt the process that speeds responses for repeated, relative to not-repeated, trials and, thereby, reveal the influence of a process that slows responses for repeated, relative to not-repeated, trials.

In Experiments 1A, 1B, and 1C, we examined the influence of an intervening event on nonspatial repetition effects, using colors (Experiment 1A), line lengths (Experiment $1 \mathrm{~B}$ ), and words (Experiment $1 \mathrm{C}$ ) as stimuli in a $2 \mathrm{AFC}$ discrimination task. In all of these experiments, the intervening event was a small colored circle that appeared centrally and that participants responded to by pressing both of two response keys upon its onset. Indeed, in all three experiments, repetition costs were observed, but only when an intervening event was responded to between consecutive targets. In Experiment 2, we confirmed that this effect was not due to a simple strategy difference for intervening event and no-intervening event trials presented in separate blocks, since the same effects were observed when these two trials types were mixed within the same block. In Experiments 3A and $3 \mathrm{~B}$, we examined whether the timing of the intervening event relative to the first and second targets was critical, as well as whether the repetition costs observed in Experiments $1 \mathrm{~A}, 1 \mathrm{~B}$, and $1 \mathrm{C}$ depend on the particular response made to the intervening event. In these experiments, we observed a repetition cost in the intervening event condition that did not depend on the timing of the intervening event and that occurred despite a change in the modality used to respond to the intervening event. In Experiment 4, the intervening event was changed from a visual stimulus (a red dot) to an auditory tone, and the results were the same; a repetition cost was observed only in the intervening event condition. Finally, in Experiment 5, we tested our initial assumption that the mere presentation of an intervening event would not be sufficient to observe an IOR-like repetition effect in nonspatial 2AFC tasks. Indeed, in this experiment, we observed a repetition benefit both with and without an intervening event.

\section{Experiments 1A, 1B, and 1C}

On each trial in Experiments 1A, 1B, and 1C, a single target appeared in a first display, which we call T1. Participants were to respond manually to this target, which ultimately led to the onset of a second target, which we call T2. A manual response that followed the same S-R mapping as for T1 was required for $\mathrm{T} 2$. T1 and $\mathrm{T} 2$ could be either of two stimuli. They were identical on half of the trials and different on half of the trials, and thus the identity of $\mathrm{T} 1$ provided no predictive information about the identity of T2. In Experiment 1A, participants were required to discriminate whether $\mathrm{T} 1$ was a blue or a yellow rectangle and then do the same for T2. In Experiment 1B, participants discriminated whether $\mathrm{T} 1$ was a short or a long line and then did the same for T2. Finally, in Experiment 1C, participants discriminated whether T1 was the word "left" or "right" and then did the same for T2.

In addition, for half of the trials in each of the two repetition conditions, a red dot appeared centrally after response to $\mathrm{T} 1$ and prior to onset of T2. On trials with this intervening event, participants were asked to respond to its onset by pressing both response keys simultaneously, which then initiated presentation of T2. Our objective was to compare repetition effects for trials that included an intervening event with those for trials that did not include an intervening event.

Again, our logic was as follows. We assumed that an episodic integration process facilitates responses to repeated trials, relative to not-repeated trials, under conventional 2AFC testing conditions. This assumption is consistent with a wide range of theoretical proposals both within the $2 \mathrm{AFC}$ repetition effect literature (Pashler \& Baylis, 1991; Rabbitt, 1968 ) and in the broader attention and performance literature (Hommel, 1998; Kahneman, Treisman, \& Gibbs, 1992; Logan, 1988, 1990). The central idea is that onset of a target event can cue the retrieval of a memory representation in 
which various attributes of a prior target event, including the response made to that target, are bound together. On repeated trials, the retrieval of this memory representation offers a more efficient basis of responding to the current target than does application of the analytic S-R rule. We assume further that response to an intervening event might selectively disrupt this episodic integration process. If these two assumptions hold, the intervening event condition should allow us to evaluate whether repetition effects in nonspatial $2 \mathrm{AFC}$ tasks are codetermined by two processes: one that speeds responses to repeated, relative to not-repeated, trials and another that slows responses to repeated, relative to notrepeated, trials. In particular, if response to an intervening event disrupts the episodic integration process, responses might well be slower for repeated trials than for notrepeated trials.

\section{Method}

Participants All participants were recruited from an introductory psychology course or a 2nd-year cognitive psychology course from McMaster University and participated for course credit. All participants had normal or corrected-tonormal vision. Twenty-five, 17, and 18 undergraduate students participated in Experiments $1 \mathrm{~A}, 1 \mathrm{~B}$, and $1 \mathrm{C}$, respectively.

Apparatus and stimuli All experiments were run on a PC using MEL experimental software. Participants sat directly in front of a 15-in. SVGA computer monitor, at a distance of approximately $57 \mathrm{~cm}$. A plus sign was presented as the fixation point in the center of the screen and subtended a visual angle of $0.6^{\circ}$ horizontally and $0.7^{\circ}$ vertically. The target stimuli were presented centrally against a black background.

In Experiment $1 \mathrm{~A}$, both $\mathrm{T} 1$ and $\mathrm{T} 2$ were either a blue or a yellow rectangle, and each subtended a visual angle of $6.3^{\circ}$ horizontally and $1.2^{\circ}$ vertically. In Experiment $1 \mathrm{~B}$, two white lines that differed in length were used as T1 and T2, rather than two rectangles that differed in color. The short line subtended a visual angle of $1.75^{\circ}$ horizontally, and the long line subtended a visual angle of $6.75^{\circ}$ horizontally. Both short and long lines subtended a visual angle of $0.2^{\circ}$ vertically. In Experiment 1C, the words "right" and "left" were used as T1 and T2. The word "right" subtended a visual angle of $4.0^{\circ}$ in width, and the word "left" subtended a visual angle of $3.0^{\circ}$ in width, while both words subtended a visual angle of $1.5^{\circ}$ in height. In all three experiments, the intervening event was a red dot presented centrally, with radius subtending $0.25^{\circ}$ of visual angle.

Procedure and design The experiment consisted of two blocked conditions: an intervening-event condition and a no-intervening-event condition. Each condition had an initial practice block consisting of 16 trials, followed by nine experimental blocks of 16 trials each.

For both conditions, each trial began with the appearance of a fixation cross in the middle of the computer screen for $1,000 \mathrm{~ms}$ and then a blank screen for $500 \mathrm{~ms}$. In the nointervening-event condition, $\mathrm{T} 1$ then appeared and remained on the screen until the participant made a keypress response. A blank interval of variable length, either 1,500 or $2,500 \mathrm{~ms}$, then followed after the keypress to T1. T2 was then presented and remained on the screen until the participant made a second keypress response. Participants were instructed to press the "/" key to indicate the presence of a blue rectangle and to press the " $\mathrm{z}$ " key to indicate the presence of a yellow rectangle in Experiment 1A. Experiments $1 \mathrm{~B}$ and $1 \mathrm{C}$ used similar response mappings, with the " $\mathrm{z}$ " key corresponding to the short line in Experiment 1B, and to the word "left" in Experiment 1C. Participants used the index finger of their left hand to press the " $z$ " key and the index finger of their right hand to press the "/" key. Response time (RT) was measured as the latency between onset of the target stimulus and keypress response.

The intervening-event condition differed from the nointervening-event condition from the point after the participant responded to T1. A blank interval of either 500 or $700 \mathrm{~ms}$ followed response to T1. The length of this interval was chosen at random between these two values, with the intention of producing some temporal uncertainty as to the onset of the intervening event. Following the blank interval, the intervening event (a red dot) appeared and remained on the screen until the participant pressed both the " $z$ " and the "/" keys in unison. After this response to the intervening event, a blank interval of either 500 or $1,500 \mathrm{~ms}$ occurred prior to onset of T2. These intervals were chosen so as to roughly equate the response-stimulus interval (RSI) for T1 and T2 across the intervening-event and no-interveningevent conditions, assuming a mean RT for the intervening event of about $400 \mathrm{~ms}$. Two RSI conditions (500 and $1,500 \mathrm{~ms}$ ) were included in the design merely as an exploratory measure of the time course of the repetition effect. The different RSIs were not meant to be contrasted against the short and long time intervals typically used in IOR studies, since even the shortest RSI condition in the interveningevent condition exceeded the shortest time interval typically used to measure facilitation effects. As was the case for T1, T2 remained on the screen until participants responded to its identity by pressing the "/" key or the " $\mathrm{z}$ " key.

For both the intervening-event condition and the nointervening-event condition, task instructions were displayed on the screen prior to the start of the practice block. Prior to each block of trials within each condition, the message "Press B to begin block" appeared, allowing participants to rest between blocks when needed. For all trials in both conditions, there was a 2,000-ms intertrial interval 
that started once a response was made to $\mathrm{T} 2$. The procedure for trials in both conditions is displayed in Fig. 1.

Three within-subjects variables were manipulated in the experiment: intervening event (no intervening event/intervening event), repetition (repeated/nonrepeated), and RSI $(1,500 \mathrm{~ms} / 2,500 \mathrm{~ms})$. The order in which participants performed the two intervening-event conditions (intervening event condition first or second) was the only betweensubjects variable and was counterbalanced across participants. The intervening-event condition was manipulated between blocks. In the no-intervening-event condition, participants responded to $\mathrm{T} 1$ and $\mathrm{T} 2$ without the appearance of a red dot between $\mathrm{T} 1$ and $\mathrm{T} 2$, whereas in the interveningevent condition, participants responded to $\mathrm{T} 1$, then to the intervening red dot by pressing both response keys, and then to T2. Repetition was manipulated within blocks. In the repeated condition, $\mathrm{T} 1$ and $\mathrm{T} 2$ were identical colored rectangles (Experiment 1A), lines (Experiment 1B), or words (Experiment 1C), whereas in the not-repeated condition, T1 and T2 were different. RSI was also manipulated within blocks. In the no-intervening-event condition, the 1,500and 2,500-ms RSI conditions were measured precisely as the latency between response to $\mathrm{T} 1$ and onset of $\mathrm{T} 2$, whereas in the intervening-event condition, these RSI values were approximate, as described above.

\section{Results}

Since our primary interest was in performance for $\mathrm{T} 2$ as a function of its relation to T1, a trial was coded as correct if responses to both $\mathrm{T} 1$ and $\mathrm{T} 2$ were correct and as an error if response to $\mathrm{T} 1$ was correct and that to $\mathrm{T} 2$ was incorrect, or vice versa. RTs for correct responses to $\mathrm{T} 2$ on all trials in Experiments $1 \mathrm{~A}, 1 \mathrm{~B}$, and $1 \mathrm{C}$ were submitted to an outlier analysis that eliminated suspiciously long RTs (Van Selst \& Jolicoeur, 1994). These outlier analyses eliminated 3.2\%, $2.9 \%$, and $3.0 \%$ of correct RTs from further analysis in Experiments 1A, 1B, and 1C, respectively. Mean RTs and error rates for each condition in each experiment were then computed on the basis of the remaining observations, and these data were submitted to mixed factor analyses of variance that included repetition (repeated or not repeated), RSI (short or long), and intervening event (intervening event or no intervening event) as within-subjects factors and order (intervening-event condition first or second) as a between-subjects factor. The alpha criterion was set to .05 for all analyses. Means RTs and error rates for each condition, collapsed across participants, are listed in Table 1 and displayed in Fig. 2 collapsed across participants and RSI (Table 2).

Our initial RT analysis included order as a variable to examine whether our counterbalancing manipulation interacted with any of the primary effects of interest. Although order did enter into a significant interaction in three of the experiments reported here, it was a different interaction in each case, and in no case did order modulate the two-way interaction between repetition and intervening event that is of most interest here. As such, order was omitted as a variable in the final analyses of both RTs and error rates, leaving us with repeated measures designs with repetition, intervening event, and RSI as factors.

Experiment $1 A$ The data from 1 participant were not included in the final analyses reported here because the RTs from
Fig. 1 The sequence of events for a not-repeated trial in the intervening-event condition of Experiment $1 \mathrm{~A}$ is shown. In the experiment, the darker rectangle would have been blue, and the lighter rectangle would have been yellow. In the no-interveningevent condition (not shown), the intervening event was replaced by a blank screen that remained for approximately the same length of time as the intervening event. Experiments 1B and $1 \mathrm{C}$ were identical in design, with the rectangles replaced by short and long lines or the words "right" and "Left," respectively

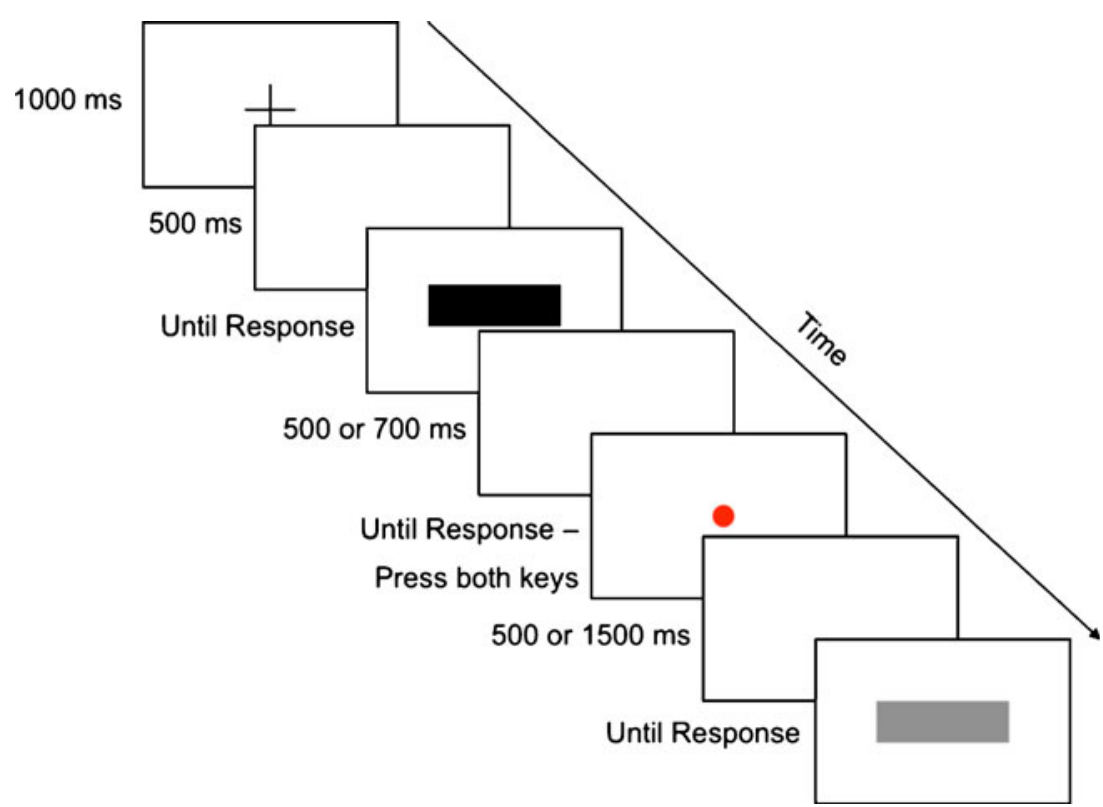


Table 1 Mean response times (in milliseconds) and error rates for T2 for each condition in Experiments 1A, 1B, 1C, 2, 3A, 3B, 4, and 5

\begin{tabular}{|c|c|c|c|c|c|c|c|}
\hline \multirow[t]{2}{*}{ Experiment } & \multirow[t]{2}{*}{ RSI } & \multicolumn{2}{|c|}{ Intervening Event Condition } & \multirow{2}{*}{$\begin{array}{l}\text { Priming Effect } \\
\text { Not Rep. -Rep. }\end{array}$} & \multicolumn{2}{|c|}{ No-Intervening Event Condition } & \multirow{2}{*}{$\begin{array}{l}\text { Priming Effect } \\
\text { Not Rep. -Rep }\end{array}$} \\
\hline & & Repeated & Not Repeated & & Repeated & Not Repeated & \\
\hline \multirow[t]{2}{*}{ 1A (Color) } & Short & $448(.04)$ & $438(.02)$ & -10 & $490(.03)$ & $524(.02)$ & 34 \\
\hline & Long & $454(.03)$ & $423(.01)$ & -31 & $483(.02)$ & $511(.01)$ & 28 \\
\hline \multirow[t]{2}{*}{ 1B (Line Length) } & Short & $491(.04)$ & $447(.02)$ & -44 & $463(.01)$ & $482(.04)$ & 19 \\
\hline & Long & $469(.04)$ & $449(.02)$ & -20 & $464(.02)$ & $466(.02)$ & 2 \\
\hline \multirow[t]{2}{*}{ 1C (Right/Left) } & Short & $490(.02)$ & $465(.02)$ & -25 & $455(.01)$ & $498(.02)$ & 43 \\
\hline & Long & $489(.03)$ & $474(.02)$ & -15 & $486(.02)$ & $483(.02)$ & -3 \\
\hline \multirow[t]{2}{*}{2 (80/20 Group) } & Short & $482(.03)$ & $463(.02)$ & -19 & $480(.01)$ & $491(.02)$ & 11 \\
\hline & Long & $497(.04)$ & $488(.02)$ & -9 & $466(.03)$ & $484(.04)$ & 18 \\
\hline \multirow[t]{2}{*}{2 (20/80 Group) } & Short & $523(.04)$ & $483(.03)$ & -40 & $507(.03)$ & $568(.02)$ & 61 \\
\hline & Long & $512(.02)$ & $494(.03)$ & -18 & $519(.03)$ & $530(.03)$ & 11 \\
\hline \multirow[t]{4}{*}{ 3A (Say "Go") } & $200 / 1900$ & $493(.03)$ & $463(.01)$ & -30 & - & - & - \\
\hline & $700 / 1400$ & $484(.04)$ & $464(.02)$ & -20 & - & - & - \\
\hline & $1300 / 800$ & $491(.03)$ & $464(.02)$ & -27 & - & - & - \\
\hline & $1800 / 300$ & $505(.04)$ & $482(.02)$ & -23 & - & - & - \\
\hline \multirow[t]{5}{*}{ 3B (Say “Go”) } & $200 / 1900$ & $620(.03)$ & $590(.03)$ & -30 & - & - & - \\
\hline & $700 / 1400$ & $578(.01)$ & $567(.02)$ & -11 & - & - & - \\
\hline & $1300 / 800$ & $606(.04)$ & $559(.02)$ & -47 & - & - & - \\
\hline & $1800 / 300$ & $665(.03)$ & $632(.03)$ & -33 & - & - & - \\
\hline & 2100 & - & - & - & $557(.03)$ & $597(.03)$ & 40 \\
\hline \multirow[t]{2}{*}{4 (Auditory) } & Short & $485(.02)$ & $461(.02)$ & -24 & $453(.01)$ & $488(.02)$ & 35 \\
\hline & Long & $460(.02)$ & $450(0.1)$ & -10 & $444(.02)$ & $468(.03)$ & 24 \\
\hline \multirow[t]{2}{*}{5 (No Response) } & Short & $503(.04)$ & $535(.04)$ & 32 & $575(.02)$ & $599(.02)$ & 24 \\
\hline & Long & $517(.03)$ & $521(.03)$ & 4 & $534(.03)$ & $577(.04)$ & 43 \\
\hline
\end{tabular}

this participant were more than two standard deviations longer than the mean RT of all participants. All analyses were conducted with and without the data from this participant, and exclusion of this participant's data did not change the pattern of results significantly.

In the analysis of RTs, there was a significant interaction between intervening event and repetition, $F(1,23)=29.11$, $p<.001, \eta_{\mathrm{p}}{ }^{2}=.56$. To examine this interaction in more detail, simple main effects of repetition were analyzed separately for the intervening-event and no-intervening-event conditions. In the intervening-event condition, RTs were longer for repeated $(451 \mathrm{~ms})$ than for not-repeated (430 ms) trials, $F(1,23)=13.48, p<.001, \eta_{\mathrm{p}}{ }^{2}=.39$. In contrast, in the no-intervening-event condition, RTs were shorter for repeated $(486 \mathrm{~ms})$ than for not-repeated (518 ms) trials, $F(1,23)=10.21, p=.004, \eta_{\mathrm{p}}{ }^{2}=.31$.

There was one additional significant statistical effect in the overall analysis of RTs that is of less theoretical significance but that we report here for the benefit of the reader. In particular, there was a significant main effect of intervening event, $F(1,23)=7.20, p=.01, \eta_{\mathrm{p}}{ }^{2}=.24$. Responses to $\mathrm{T} 2$ were faster with an intervening event (441 ms) than without an intervening event $(502 \mathrm{~ms})$. This effect may have occurred because the intervening event acted as a warning signal to allow participants to better predict the onset of T2 (Bertelson, 1967). In the analysis of error rates, there were no statistically significant effects.

Experiment $1 B$ In the analysis of RTs, there was a significant three-way interaction between repetition, intervening event, and RSI, $F(1,16)=15.42, p=.004, \eta_{\mathrm{p}}{ }^{2}=.41$. To examine this interaction further, separate ANOVAs were conducted for the short and long RSIs.

For the short-RSI condition, there was a significant interaction between repetition and intervening event, $F(1,16)=$ $15.63, p=.001, \eta_{\mathrm{p}}{ }^{2}=.49$. Responses were slower for repeated trials $(491 \mathrm{~ms})$ than for not-repeated trials $(447 \mathrm{~ms})$ in the intervening-event condition, $F(1,16)=24.10, p<.001$, $\eta_{\mathrm{p}}{ }^{2}=.60$, whereas responses were numerically faster for repeated trials $(463 \mathrm{~ms})$ than for not-repeated trials $(482 \mathrm{~ms})$ in the no-intervening-event condition, although the latter effect only approached significance, $p<.10$. In other words, the pattern of results for the short-RSI condition was similar to that observed in Experiment 1A. 


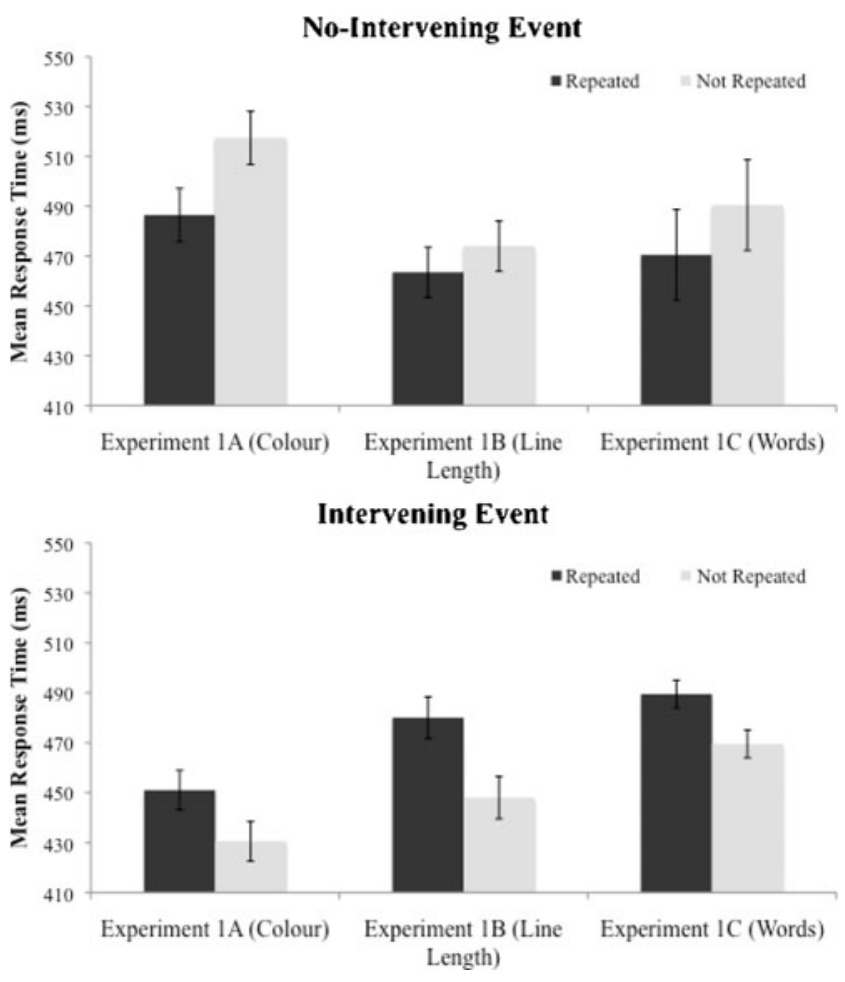

Fig. 2 Top panel: Mean response times for T2 in Experiments 1A, 1B, and $1 \mathrm{C}$ (no-intervening-event condition), collapsed across RSI and participants. Bottom panel: Mean response times for T2 in Experiments 1A, 1B, and 1C (intervening-event condition), collapsed across RSI and participants. Error bars represent the standard error of the difference between repeated and not-repeated conditions

For the long-RSI condition, the interaction between repetition and intervening event failed to reach significance, $p=$ .06 . However, the direction of the interaction is consistent with that observed in the short-RSI condition, with the only difference being that the repetition priming effect for the short RSI appeared not to persist to a long RSI for the nointervening-event condition.

In the analysis of error rates, there was a significant interaction between repetition and intervening event, $F(1$,
16) $=5.25, p=.03, \eta_{\mathrm{p}}{ }^{2}=.23$. To examine this effect further, separate analyses were conducted for the intervening-event and no-intervening-event conditions. In the interveningevent condition, more errors were made on repeated trials (.04) than on not-repeated trials $(.02), F(1,16)=5.28, p=$ $.03, \eta_{\mathrm{p}}{ }^{2}=.24$. In the no-intervening-event condition, the difference in error rates between repeated (.01) and notrepeated (.03) conditions was in the opposite direction but failed to reach significance, $p>.10$. Importantly, the direction of this interaction is consistent with that reported for the mean RTs, ruling out a speed-accuracy trade-off interpretation of the RT results.

Experiment $1 \mathrm{C}$ In the analysis of RTs, there was a significant interaction between intervening event and repetition, $F(1,17)=16.51, p<.001, \eta_{\mathrm{p}}{ }^{2}=.49$. This interaction was examined further by conducting separate analyses for the intervening-event and no-intervening-event conditions. In the intervening-event condition, responses were slower for repeated trials $(489 \mathrm{~ms})$ than for not-repeated trials (470 ms), $F(1,17)=18.87, p<.001, \eta_{\mathrm{p}}{ }^{2}=.53$. In contrast, in the no-intervening-event condition, responses were faster for repeated trials $(471 \mathrm{~ms})$ than for not-repeated trials (490 ms), $F(1,17)=5.84, p=.03, \eta_{\mathrm{p}}^{2}=.26$.

There were no other significant effects in the analysis of RTs and no significant effects in the analysis of error rates.

\section{Discussion}

The results of the three experiments were all very similar and straightforward. One critical result is that responses were faster for repeated targets than for not-repeated targets in the no-intervening-event condition. This result should not come as a surprise, since similar results were first reported in 2AFC tasks half a century ago (e.g., Bertelson, 1961). Clearly, there is nothing inherent in our procedure that
Table 2 Mean response times (in milliseconds) and error rates for $\mathrm{T} 1$ and the intervening event (where applicable) in Experiment 1A, 1B, 1C, 2, 3A, $3 \mathrm{~B}, 4$, and 5

\begin{tabular}{|c|c|c|c|c|}
\hline \multirow[t]{2}{*}{ Experiment } & \multicolumn{2}{|c|}{ Intervening Event Condition } & \multicolumn{2}{|c|}{ No-Intervening Event Condition } \\
\hline & $\mathrm{T} 1$ & Intervening Event & $\mathrm{T} 1$ & - \\
\hline $1 \mathrm{~A}$ & $461(.04)$ & 431 & $453(.02)$ & - \\
\hline 1B & $468(.03)$ & 409 & $472(.03)$ & - \\
\hline $1 \mathrm{C}$ & $455(.03)$ & 385 & $463(.04)$ & - \\
\hline 2 (80/20 Group) & $485(.03)$ & 409 & $488(.03)$ & - \\
\hline 2 (20/80 Group) & $501(.04)$ & 486 & $492(.02)$ & - \\
\hline 3A (Say “Go”) & $578(.03)$ & 636 & - & - \\
\hline 3B (Say “Go") & $581(.02)$ & 656 & $590(.01)$ & - \\
\hline 4 (Auditory) & $457(.02)$ & 506 & $468(.02)$ & - \\
\hline 5 (No Response) & $499(.01)$ & - & $490(.03)$ & - \\
\hline
\end{tabular}


makes observing repetition priming effects for consecutive targets difficult to measure. With this result as context, the results in the intervening-event condition are striking. With an intervening event, responses were slower for repeated than for not-repeated targets. As was noted above, we assume that the intervening event eliminated, or greatly reduced, the contribution of an episodic integration process that facilitates performance for repeated, relative to not-repeated, targets. In the absence of such a process, an effect is revealed that implicates more efficient processing of not-repeated, relative to repeated, targets.

Although the overall pattern of results was quite consistent across the experiments, the repetition benefit in the nointervening-event condition was not significant for the longRSI condition in Experiments $1 \mathrm{~B}$ and $1 \mathrm{C}$. This result may be related to one reported long ago by Kirby (1976), in which the repetition benefit declines with increasing RSI and ultimately reverses to a repetition cost in some cases. Kirby attributed this effect to an increasing expectation for alternation with increasing RSI. This issue is discussed in more detail in the General Discussion section, but the key point here is that the reversal of the repetition effect as a function of the intervening event manipulation, which is observed in the short-RSI condition in all of the experiments, merits further study.

\section{Experiment 2}

In Experiments $1 \mathrm{~A}-1 \mathrm{C}$, intervening-event trials were presented in a separate block from no-intervening-event trials. As a result, the qualitatively opposite repetition effects for these two conditions could be attributed to different blockwide strategies adopted by participants. To address whether this was the case, intervening-event trials and nointervening-event trials were mixed at random throughout the testing session in Experiment 2. To address further the contribution of strategies to the different repetition effects for intervening-event and no-intervening-event trials, the relative proportion of these two trial types was manipulated between two groups of participants. For one group (80/20 group), intervening-event trials occurred $80 \%$ of the time, and no-intervening-event trials occurred $20 \%$ of the time. For the other group (20/80 group), these proportions were reversed. To the extent that the blocked manipulation of the intervening-event conditions was responsible for the results of Experiments $1 \mathrm{~A}-1 \mathrm{C}$, different results ought to be observed in the $80 / 20$ group than in the $20 / 80$ group in this experiment. In particular, repetition effects ought to align with the trial type that is most frequent for that group; repetition costs for the $80 / 20$ group and repetition benefits for the 20/80 group. However, if strategies played a minimal role in the results observed in Experiments $1 \mathrm{~A}-1 \mathrm{C}$, repetition effects ought to align with the intervening-event type, regardless of group, with repetition costs observed for intervening-event trials and repetition benefits observed for no-intervening-event trials.

\section{Method}

Participants Twenty-four McMaster University undergraduate students recruited from either an introductory psychology course or a 2nd-year cognitive psychology course participated for course credit or $\$ 10$ remuneration. All participants had normal or corrected-to-normal vision.

Apparatus and stimuli The apparatus and stimuli used in this experiment were the same as those in Experiment 1A.

Procedure and design The procedure used in this experiment was the same as that in Experiment 1A, with the following exceptions. Instead of presenting the two intervening-event conditions (intervening event/ no intervening event) in separate blocks, intervening-event trials and no-intervening event trials were mixed at random across the experimental session. Additionally, participants were randomly assigned to one of two experimental groups: The 80/20 group had $80 \%$ intervening-event trials and $20 \%$ nointervening-event trials, while the 20/80 group had the reverse proportions of these two trial types.

\section{Results}

Correct trials were defined as in Experiments 1A, 1B, and $1 \mathrm{C}$. RTs for correct responses to $\mathrm{T} 2$ were submitted to the same outlier elimination procedure as that used in the prior experiments (Van Selst \& Jolicoeur, 1994), which resulted in the exclusion of $2.2 \%$ of the RTs from further analysis. Mean RTs in each condition were then computed on the basis of the remaining observations, and these mean RTs and corresponding error rates were submitted to mixed analyses of variance that treated repetition (repeated or not repeated), RSI (short or long), and intervening event (intervening event or no intervening event) as within-subjects factors and proportion $(80 / 20$ or $20 / 80)$ as a between-subjects factor. The alpha criterion was set to .05 for all analyses. Mean RTs and error rates for each condition, collapsed across participants, are listed in Table 1, and the mean RTs are displayed in Fig. 3.

In the analysis of RTs, there was a significant main effect of proportion, $F(1,24)=8.9, p=.042, \eta_{\mathrm{p}}{ }^{2}=.27$. Responses by participants in the $80 / 20$ group were faster $(481 \mathrm{~ms})$ than responses by participants in the $20 / 80$ group $(517 \mathrm{~ms})$. Tellingly, proportion did not interact with any of the other within-subjects factors, which suggests that strategies 


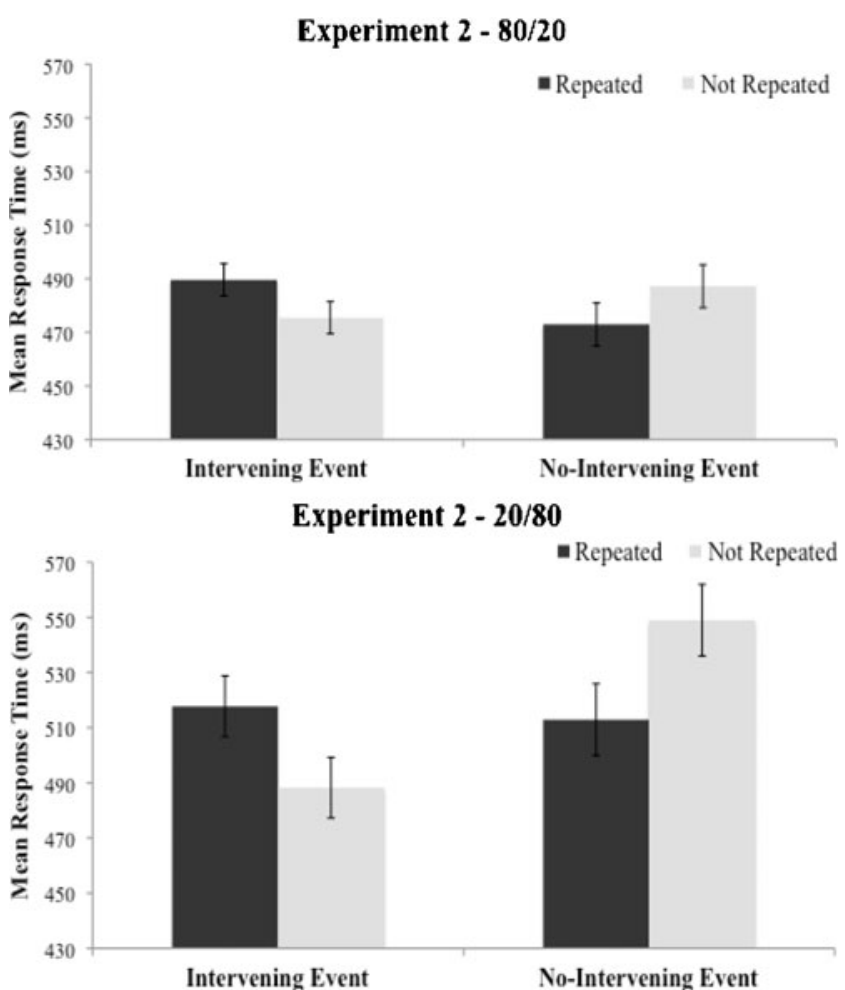

Fig. 3 Top panel: Mean response times for T2, collapsed across RSI and participants, are shown for the 80/20 group. Bottom panel: Mean response times for T2, collapsed across RSI and participants, are shown for the 20/80 group. Error bars represent the standard error of the difference between repeated and not-repeated conditions

adopted for the majority trial type played little role in determining the repetition effects.

However, as in Experiments $1 \mathrm{~A}-1 \mathrm{C}$, there was a significant interaction between repetition and intervening event, $F(1,24)=21.9, p<.0001, \eta_{\mathrm{p}}^{2}=.65$. Simple main effect analyses were performed to interpret this interaction. In the intervening-event condition, responses were slower for repeated trials $(504 \mathrm{~ms})$ than for not-repeated trials $(482 \mathrm{~ms})$, $F(1,12)=14.1, p=.0028, \eta_{\mathrm{p}}{ }^{2}=.54$. In the no-interveningevent condition, responses were faster for repeated trials $(492 \mathrm{~ms})$ than for not-repeated trials $(518 \mathrm{~ms}), F(1,12)=$ $13.9, p=.0029, \eta_{\mathrm{p}}^{2}=.53$.

There were no significant effects in the analyses of error rates.

\section{Discussion}

The results of Experiment 2 show the same pattern of repetition effects as in Experiments $1 \mathrm{~A}-1 \mathrm{C}$, despite the intervening-event manipulation being intermixed rather than blocked. A repetition cost was observed in the interveningevent condition, and a repetition benefit was observed in the no-intervening-event condition. Moreover, there was no evidence that manipulating whether intervening-event trials constituted the majority or minority of the trials impacted this pattern of results. Clearly, the pattern of repetition effects observed in Experiments 1A-1C and Experiment 2 cannot be explained by reference to strategy differences allowed by presenting the two intervening-event conditions in separate blocks.

\section{Experiments 3A and 3B}

Experiments $3 \mathrm{~A}$ and $3 \mathrm{~B}$ were similar to Experiment $1 \mathrm{~A}$ in that manual $2 \mathrm{AFC}$ responses were required to $\mathrm{T} 1$ and $\mathrm{T} 2$. However, these experiments were conducted to address two important issues related to our dual-process interpretation of the results of the prior experiments. One issue concerned the relation between the response made to the intervening event and the responses made to $\mathrm{T} 1$ and $\mathrm{T} 2$. To address whether making task-relevant responses to the intervening event (i.e., responding to $\mathrm{T} 1, \mathrm{~T} 2$, and the intervening event with the same buttons) was critical to the results observed in Experiments $1 \mathrm{~A}-1 \mathrm{C}$, in this experiment participants were required simply to say "go" aloud upon onset of the intervening event. If making task-relevant responses to the intervening event was critical to the repetition costs observed in Experiments 1A1C, a similar repetition cost should not be observed here. In contrast, if some more general form of engagement of attention in the intervening event was critical, we might well observe the same repetition cost in this experiment as in the prior experiments.

A second issue concerned the timing of the intervening event, relative to $\mathrm{T} 1$ and $\mathrm{T} 2$. The rationale for manipulating this factor was rooted in the potential for episodic memory to explain both repetition benefits in the no-interveningevent condition and repetition costs in the interveningevent condition. Hommel (1998; for related discussions, see also Kahneman et al., 1992; Milliken, Joordens, Merikle, \& Seiffert, 1998; Neill \& Mathis, 1998) outlined a framework for interpreting repetition effects in which onset of a target cues the retrieval of a representation of the immediately preceding $\mathrm{S}-\mathrm{R}$ episode, which he called an event file. A principle that predicts performance efficiency well across a broad range of experimental contexts is that partial matches between event files for consecutive targets slow performance, relative to both perfect matches and complete mismatches. According to this principle, performance might well be slow for repeated targets in the intervening-event condition because the intervening event disrupts the perfect match between $\mathrm{T} 1$ and $\mathrm{T} 2$. Indeed, processing of the intervening event might well be bound temporally to the processing of $\mathrm{T} 1$, implying that a repeated $\mathrm{T} 2$ would cue the retrieval not only of $\mathrm{T} 1$ processing, but also of $\mathrm{T} 1$ processing bound together with that associated with the intervening event. In turn, retrieval of processing 
associated with the intervening event might interfere with processing of a repeated $\mathrm{T} 2$ and, ultimately, slow responding.

In Experiments $3 \mathrm{~A}$ and $3 \mathrm{~B}$, we tested the possibility that the intervening event introduces retrieval interference by virtue of being temporally bound to the $\mathrm{T} 1 \mathrm{~S}-\mathrm{R}$ episode. Our initial hypothesis was that intervening events presented closer in time to T1 would be more likely to be encompassed in the same episodic representation than would intervening events presented further away in time from $\mathrm{T} 1$, resulting in greater partial match costs when $\mathrm{T} 2$ is identical to T1. Experiments 3A and 3B differed only in that nointervening-event trials were not included in Experiment $3 \mathrm{~A}$, while equal numbers of intervening-event and nointervening-event trials were intermixed at random in the test session of Experiment 3B. Our aim here was to examine whether uncertainty about the eventual occurrence of an intervening event (in Experiment 3B) would modulate the episodic integration processes described above. To foreshadow our results, the timing of the intervening event had no influence on the repetition effect at all, and this was true both when intervening events occurred on every trial (Experiment $3 \mathrm{~A}$ ) and when intervening-event and nointervening-event trials were intermixed at random (Experiment 3B). As such, we found no evidence favoring the partial match interpretation offered above.

\section{Method}

Participants Twenty-four McMaster University undergraduate students (12 participants in Experiment $3 \mathrm{~A}$ and 12 participants in Experiment 3B) recruited from either an introductory psychology course or a 2nd-year cognitive psychology course participated for course credit. All participants had normal or corrected-to-normal vision.

Apparatus and stimuli The apparatus and stimuli used in this experiment were the same as those in Experiment 1A, with the exception that a voice key was used to record the onset of the participant's response to the intervening event.

Procedure and design The procedure used in this experiment was the same as that in Experiment 1A, with the following exceptions. First, participants were instructed to say "go" when the intervening dot was presented between $\mathrm{T} 1$ and T2. A voice key detected the onset of this vocal response, and the red dot was immediately removed from the screen. The experimenter coded each trial as usable or a spoil. A spoil was defined as any trial on which a noise other than that of the participant's "go" response triggered the voice key. Data from spoiled trials were not included in any further statistical analysis. Second, the time intervals between response to $\mathrm{T} 1$ and onset of the intervening event
(RSI-1) and between response to the intervening event and onset of T2 (RSI-2) varied within subjects and randomly from trial to trial across four levels. In the 200/1,900 condition, RSI-1 was $200 \mathrm{~ms}$, while RSI- 2 was $1,900 \mathrm{~ms}$. The remaining conditions were labeled and defined similarly as $700 / 1,400,1,300 / 800$, and 1,800/300. The sum of RSI- 1 and RSI-2 in all conditions was $2,100 \mathrm{~ms}$, and assuming a $400-\mathrm{ms}$ RT for the intervening event, the RSI between response to T1 and onset of T2 was the same as the long RSI in Experiments $1 \mathrm{~A}-1 \mathrm{C}$.

The only distinction between Experiments $3 \mathrm{~A}$ and 3B was that no-intervening-event trials were not included in Experiment 3A, while equal numbers of intervening-event and no-intervening-event trials were mixed at random within the tests session in Experiment 3B.

\section{Results}

Correct trials were defined as in Experiments 1A, 1B, and 1C. RTs for correct responses to T2 were submitted to the same outlier elimination procedure as that used in the prior experiments (Van Selst \& Jolicoeur, 1994), which resulted in the exclusion of $2.8 \%$ (Experiment $3 \mathrm{~A}$ ) and $3.0 \%(\mathrm{Ex}-$ periment $3 \mathrm{~B}$ ) of the RTs from further analysis. ${ }^{1}$ Additionally, $1.8 \%$ of the trials in Experiment $3 \mathrm{~A}$ and $2.4 \%$ of the trials in Experiment $3 \mathrm{~B}$ were excluded because of microphone failures for intervening-event responses. Mean RTs in each condition were then computed on the basis of the remaining observations, and these mean RTs and corresponding error rates were submitted to repeated measures analyses of variance that treated repetition (repeated/not repeated) and RSI $(200 / 1,900,700 / 1,400,1,300 / 800,1,800 / 300)$ as withinsubjects factors for Experiment 3A. The same withinsubjects factors were included in analysis of interveningevent trials in Experiment 3B, and an additional analysis was conducted for the no-intervening-event trials only. The alpha criterion was set to .05 for all analyses. Means RTs and error rates for each condition in Experiment 3A, collapsed across participants, are listed in Table 1, along with the mean RTs and error rates for each condition in Experiment 3B. The mean RTs for both Experiments $3 \mathrm{~A}$ and $3 \mathrm{~B}$ are displayed in Fig. 4.

Experiment $3 A$ In the analysis of RTs, there was a significant main effect of repetition, $F(1,11)=18.68, p<.001, \eta_{\mathrm{p}}{ }^{2}=$

\footnotetext{
${ }^{1}$ Two participants in Experiment 3B displayed longer overall RTs $(821 \mathrm{~ms}$ and $687 \mathrm{~ms}$ ) relative to the overall mean for all participants $(597 \mathrm{~ms})$. We conducted separate analyses both with and without those 2 participants, which did not reveal any differences in the overall pattern of RTs. We decided to keep both participants in the analyses to maintain an equal number of participants for both Experiments $3 \mathrm{~A}$ and $3 \mathrm{~B}$.
} 


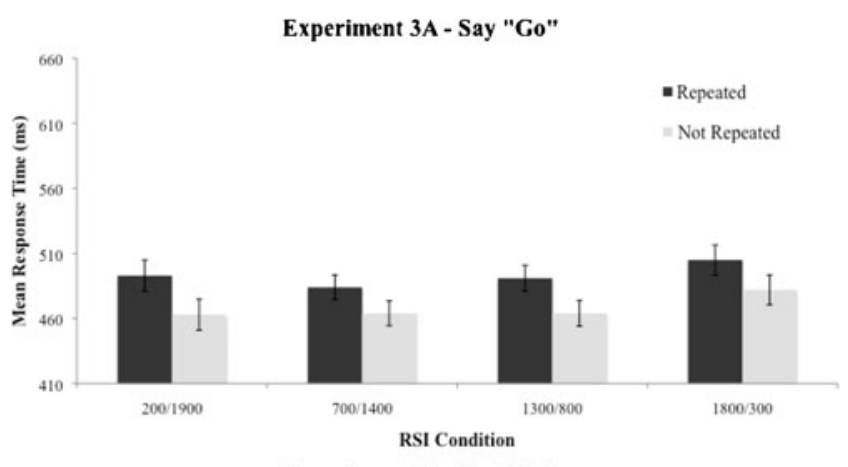

Experiment 3B - Say "Go"

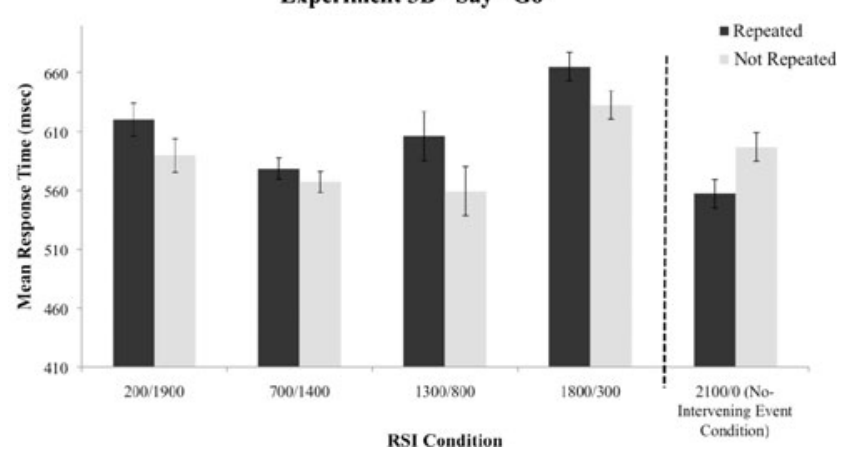

Fig. 4 Top panel: Mean response times for T2 across four different RSI conditions in Experiment 3A, collapsed across participants. Error bars represent the standard error of the difference between repeated and not-repeated conditions. Bottom panel: Mean response times for T2 across four different RSI conditions in the intervening-event condition and the single RSI condition in the no-intervening-event condition, for Experiment 3B, collapsed across participants. Error bars represent the standard error of the difference between repeated and not-repeated conditions

.63. Responses for repeated trials were slower $(493 \mathrm{~ms})$ than responses for not-repeated trials $(468 \mathrm{~ms})$. Interestingly, this main effect did not vary as a function of RSI, $p>.10$. Finally, although not of any obvious theoretical importance, there was a significant main effect of RSI, $F(3,33)=3.42, p=$ $.02, \eta_{\mathrm{p}}{ }^{2}=.24$, which appeared to be due to particularly slow responses for the 1,800/300 RSI condition. There were no significant effects in the analysis of error rates.

Experiment $3 B$ The analysis of the intervening event trials revealed a significant main effect of repetition, $F(1,11)=$ $6.5, p=.03, \eta_{\mathrm{p}}{ }^{2}=.28$. Responses were slower for repeated trials $(617 \mathrm{~ms})$ than for not-repeated trials $(587 \mathrm{~ms})$. Importantly, the effect of repetition did not vary as a function of the RSI, $p>.4$. However, there was a significant main effect of RSI, $F(3,33)=9.7, \eta_{\mathrm{p}}{ }^{2}=.39$. A post hoc Tukey test revealed that responses were significantly slower in the $1,800 / 300$ RSI condition (648 ms) than in the other three RSI conditions $(604,572$, and $582 \mathrm{~ms}$, for the 200/1,900, 700/1,400, and 1,300/800 RSI conditions, respectively).

A separate analysis of the no-intervening-event trials revealed a significant main effect of repetition, $F(1,11)=$
$7.8, p=.02, \eta_{\mathrm{p}}{ }^{2}=.30$. Responses were faster for repeated trials $(557 \mathrm{~ms})$ than for not-repeated trials $(596 \mathrm{~ms})$.

No significant effects were found in the analyses of variance for error rates.

\section{Discussion}

The key result in this experiment was that a repetition cost was observed despite the fact that the intervening event was responded to vocally by saying "go," rather than by manually using the same response keys for $\mathrm{T} 1$ and $\mathrm{T} 2$. This result rules out the idea that the repetition costs observed in Experiments $1 \mathrm{~A}-1 \mathrm{C}$ were related to the specific motor response made to the intervening event. Instead, it appears that a more general form of disruption, perhaps brought about by any form of responding to an intervening event, is sufficient to produce a repetition cost. Additionally, the results from this experiment offer no support for the idea that repetition costs in the intervening event condition depend on the proximity of the timing of the intervening event to $\mathrm{T} 1$.

\section{Experiment 4}

Whereas, in Experiment 3, we changed the response to the intervening event from a manual keypress to a vocal response, in Experiment 4 we changed the presentation of the intervening from the visual modality to the auditory modality. In particular, the intervening event in this experiment was an auditory tone, and participants responded to it as in Experiment 1 by pressing both response keys upon its onset. This experiment allowed us to test whether the reversal of the repetition effect in the intervening event condition depends on presentation of the intervening event in the same modality as $\mathrm{T} 1$ and $\mathrm{T} 2$.

\section{Method}

Participants Eighteen McMaster University undergraduate students recruited from either an introductory psychology course or a 2nd-year cognitive psychology course participated for course credit. All participants had normal or corrected-to-normal vision.

Apparatus and stimuli The apparatus and stimuli used in this experiment were the same as those in Experiment 1A, with the exception that a high-frequency tone $(1,000 \mathrm{~Hz})$ was presented as the intervening event.

Procedure and design The procedure used in this experiment was the same as that in Experiment 1A, with one 
exception. In the intervening-event condition, a tone was presented from the CPU speakers as the intervening event. Participants were instructed to respond to the tone by pressing the "blue" and "yellow" buttons down at the same time, as in Experiment 1A, which would cease the presentation of the tone.

\section{Results}

Correct trials were defined as in Experiments 1A, 1B, and 1C. RTs for correct responses to T2 were submitted to the same outlier elimination procedure as that used in the prior experiments (Van Selst \& Jolicoeur, 1994), which resulted in the exclusion of $2.9 \%$ of the RTs from further analysis. Mean RTs in each condition were then computed on the basis of the remaining observations, and these mean RTs and corresponding error rates were submitted to repeated measures analyses of variance that treated repetition (repeated/not repeated), RSI (short/long), and intervening event (intervening event or no intervening event) as within-subjects factors. The alpha criterion was set to .05 for all analyses. Mean RTs and error rates for each condition, collapsed across participants, are listed in Table 1. Repetition effects for the two intervening event conditions are contrasted in Fig. 5.

The analysis of RTs revealed a significant repetition $\times$ intervening-event interaction, $F(1,17)=15.87, p<.001$, $\eta_{\mathrm{p}}{ }^{2}=.48$. In the intervening-event condition, RTs were faster for the not-repeated condition $(455 \mathrm{~ms})$ than for the repeated condition $(473 \mathrm{~ms}), F(1,17)=5.39, p=.03, \eta_{\mathrm{p}}{ }^{2}=$ .24. In the no-intervening-event condition, RTs were shorter for the repeated condition $(443 \mathrm{~ms})$ than for the not-repeated condition $(474 \mathrm{~ms}), F(1,17)=12.14, p=.003, \eta_{\mathrm{p}}{ }^{2}=.42$.

Also, from the omnibus ANOVA, the effect of RSI was significant, $F(1,17)=5.32, p=.03, \eta_{\mathrm{p}}{ }^{2}=.24$, which was due to RTs at short RSIs being longer $(467 \mathrm{~ms})$ than RTs at long RSIs (455 ms). No additional effects or interactions

\section{Experiment 4 - Auditory Intervening Event}

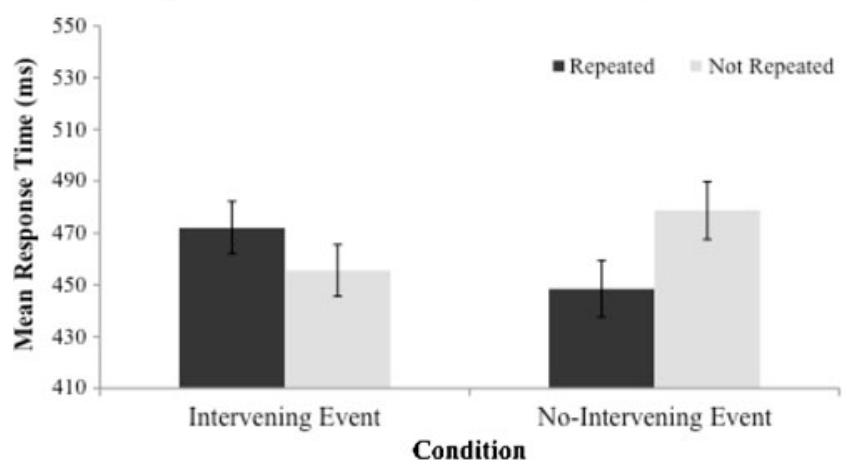

Fig. 5 Mean response times for T2 in Experiment 4, collapsed across RSI and participants. Error bars represent the standard error of the difference between repeated and not-repeated conditions came out significant in the omnibus ANOVA. There were no significant effects in the overall analysis of error rates.

\section{Discussion}

The results were similar to those observed Experiments 1A1C. In the no-intervening-event condition, responses were faster for repeated than for not-repeated trials. In contrast, in the intervening-event condition, responses were slower for repeated trials than for not-repeated trials. As in the prior experiments, we assume that the requirement to respond to the intervening event disrupted an episodic integration process that would otherwise have produced faster responses for repeated, relative to not-repeated, trials. The results of Experiments 3A, 3B, and 4 together suggest that the disruption of this episodic integration process does not require the response modality for the intervening event to match that for $\mathrm{T} 1$ and $\mathrm{T} 2$ and that it does not require the stimulus modality of the intervening event to match that for $\mathrm{T} 1$ and $\mathrm{T} 2$.

\section{Experiment 5}

In Experiments 1A-1C, 2, 3A-3B, and 4, we learned that either a manual response that overlapped with that used to respond to $\mathrm{T} 1$ and $\mathrm{T} 2$ or a vocal response that was quite dissimilar to that used to respond to T1 and T2 was sufficient to reverse the repetition benefit to a repetition cost. The issue addressed in this experiment is whether visual presentation of the intervening event on its own, without any response at all, is sufficient to produce such an effect. To address this issue, we replicated Experiment 1A, with the exception that no response was required to the intervening event in the intervening-event condition.

The results of prior studies might lead one to believe that the mere presentation of an intervening event would be sufficient to reverse the repetition benefit to a repetition cost (Fox \& de Fockert, 2001; Law et al., 1995). However, these studies used a cue-target procedure in which a response was required only to the second of two events on a trial. When a response is made to both of two events on a trial, it seems reasonable to assume that an S-R episode for the first event becomes available for use when responding to a repeated second event, a process that we call episodic integration. Whether something other than mere presentation of an intervening event is needed to disrupt this episodic integration process was the focus of this experiment.

\section{Method}

Participants Twenty-four McMaster University undergraduate students recruited from either an introductory psychology course or a 2nd-year cognitive psychology course 
participated for course credit. All participants had normal or corrected-to-normal vision.

Apparatus and stimuli The apparatus and stimuli used in this experiment were the same as those in Experiment 1A.

Procedure and design The procedure used in this experiment was the same as that in Experiment 1A, with two exceptions. First, participants were not instructed to respond to the presence of the intervening event and, instead, were told that the intervening event would disappear from the screen after a short duration. The second change concerned the length of time the intervening event appeared on the screen. Rather than remaining on the screen until response, the intervening event appeared for $500 \mathrm{~ms}$ and then disappeared.

\section{Results}

Correct trials were defined as in prior experiments. RTs for correct responses to $\mathrm{T} 2$ were submitted to the same outlier elimination procedure used in prior experiments (Van Selst \& Jolicoeur, 1994), which resulted in the exclusion of $2.9 \%$ of the RTs from further analysis. Mean RTs in each condition were then computed on the basis of the remaining observations, and these mean RTs and corresponding error rates were submitted to repeated measures analyses of variance that treated repetition (repeated/not repeated), RSI (short/long), and intervening event (intervening event or no intervening event) as within-subjects factors. The alpha criterion was set to .05 for all analyses. Mean RTs and error rates for each condition, collapsed across participants, are listed in Table 1. Repetition effects for the two interveningevent conditions are contrasted in Fig. 6.

The data from 1 participant were not included in the final analyses reported here because the mean RT for that

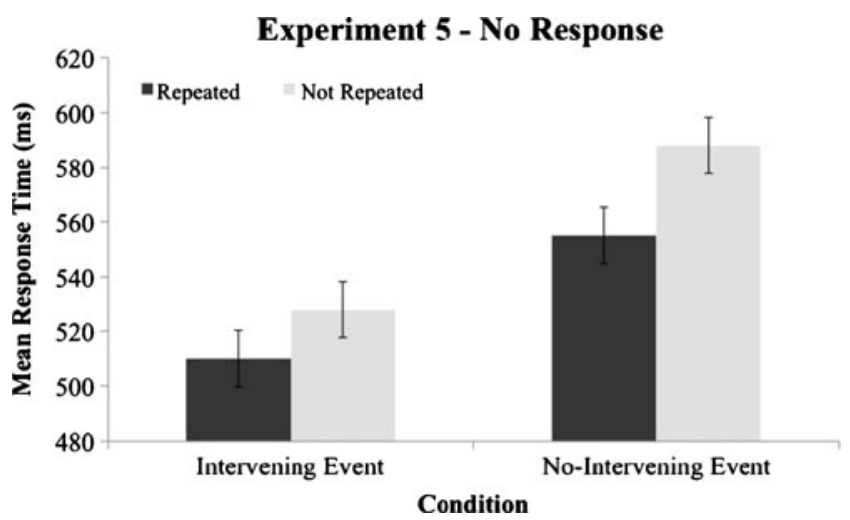

Fig. 6 Mean response times for T2 in Experiment 5, collapsed across RSI and participants. Error bars represent the standard error of the difference between repeated and not-repeated conditions participant differed from the mean RT of all participants by more than two standard deviations. All analyses were conducted with and without the data from this participant, and exclusion of this participant's data did not change the pattern of results significantly.

In the analysis of RTs, there was a significant interaction between intervening event and repetition, $F(1,23)=3.19, p=$ $.03, \eta_{\mathrm{p}}{ }^{2}=.32$. Simple main effects were analyzed separately for the intervening-event and no-intervening-event conditions. In the intervening-event condition, RTs were shorter for repeated trials $(510 \mathrm{~ms})$ than for not-repeated trials $(528 \mathrm{~ms}), F(1,23)=4.59, p=.02, \eta_{\mathrm{p}}{ }^{2}=.24$. Similarly, in the no-intervening-event condition, RTs were shorter for repeated trials $(554 \mathrm{~ms})$ than for not-repeated trials (588 ms), $F(1,23)=10.91, p=.006, \eta_{\mathrm{p}}{ }^{2}=.31$. Thus, rather than reversing the repetition effect, in this case the intervening event produced a modest attenuation of the repetition benefit, a benefit that remained significant for both intervening-event conditions.

Several other effects with less obvious theoretical significance were significant in the overall analysis of RTs. The intervening event $\times$ RSI interaction was significant, $F(1,23)=9.21, p=.01, \eta_{\mathrm{p}}{ }^{2}=.35$. Analysis of simple main effects revealed no significant difference between trials with a short RSI $(519 \mathrm{~ms})$ and trials with a long RSI (519 ms), $F(1,23)<1$, in the intervening-event condition. In contrast, trials with a short RSI were responded to slower $(587 \mathrm{~ms})$ than trials with a long RSI $(555 \mathrm{~ms}), F(1,23)=$ 28.97, $p<.001, \eta_{\mathrm{p}}{ }^{2}=.39$, in the no-intervening-event condition. There was also a significant main effect of intervening event, $F(1,23)=8.39, p=.003, \eta_{\mathrm{p}}{ }^{2}=.33$. Responses for trials with an intervening event were faster $(519 \mathrm{~ms})$ than those for trials without an intervening event $(571 \mathrm{~ms})$. There was a significant main effect of RSI, $F(1$, $23)=6.52, p=.03, \eta_{\mathrm{p}}{ }^{2}=.29$. Responses for trials with a short RSI were slower $(553 \mathrm{~ms})$ than those for trials with a long RSI $(537 \mathrm{~ms})$. Finally, there was a significant main effect of repetition, $F(1,23)=10.02, p=.003, \eta_{\mathrm{p}}{ }^{2}=.35$. Responses for repeated trials were faster $(532 \mathrm{~ms})$ than those for not-repeated trials $(558 \mathrm{~ms})$.

In the analysis of error rates, there was a significant interaction between intervening event and RSI, $F(1,23)=$ $8.75, p=.01, \eta_{\mathrm{p}}^{2}=.24$. Simple main effects analyses revealed that in the intervening-event condition, more errors were made on trials with a short RSI (.04) than on trials with a long RSI (.03), $F(1,23)=8.90, p=.02, \eta_{\mathrm{p}}{ }^{2}=.28$. In the no-intervening-event condition, there was no significant difference between trials with short and long RSIs.

\section{Discussion}

The critical finding from Experiment 5 was that responses to repeated targets were faster than responses to not-repeated 
targets in the intervening-event condition. This result contrasts with those in Experiments 1A-1C, 2, 3A-3B, and 4, in which a response to an intervening event resulted in repetition costs rather than repetition benefits. At least in this experimental context, then, the mere presentation of an intervening event on its own was not sufficient to reverse the repetition benefit to a repetition cost. Whether this result occurred because participants learned not to attend to the intervening event when a response to this event was not required or because responding to the intervening event itself is critical to the effect is an issue that merits further study.

\section{General discussion}

The results of the present study were straightforward. The repetition benefit customarily seen in 2AFC tasks reversed to a repetition cost when participants responded to an intervening event presented between $\mathrm{T} 1$ and $\mathrm{T} 2$. This reversal of the repetition effect occurred when participants responded to the intervening event by simultaneously pressing the two manual response keys used to respond to T1 and T2 (Experiments $1 \mathrm{~A}, 1 \mathrm{~B}$, and $1 \mathrm{C}$ ), when intervening-event trials were mixed with no-intervening-event trials (Experiments 2 and 3B), when participants responded to the intervening event merely by saying "go" aloud (Experiments $3 \mathrm{~A}$ and $3 \mathrm{~B}$ ), and when the intervening event was presented aurally (Experiment 4). In contrast, when the intervening event appeared but was not responded to, the customary repetition benefit was observed (Experiment 5). Together, these results demonstrate clearly that attending and responding to an intervening event has the effect of reversing the repetition effect in $2 \mathrm{AFC}$ tasks.

We proposed a dual-process account of these results, in which one process that speeds performance for repetitions operates concurrently with another process that slows performance for repetitions. This opposition between two concurrent processes is the key property of the dual-process account offered here and holds even if there remains some debate about the precise nature of the processes themselves. From this perspective, the key finding here is that response to an intervening event affects the relative contributions of these two processes. Under usual testing conditions in $2 \mathrm{AFC}$ procedures, although both processes may contribute to performance, the contribution of a process that speeds performance for repetitions outweighs the influence of a process that slows performance for repetitions, together producing faster responses for repeated trials than for notrepeated trials. In contrast, in the intervening-event conditions of the experiments reported here, we propose that the influence of a process that speeds performance for repeated trials was disrupted, thus revealing the influence of a process that slows performance for repeated trials.
This dual-process proposal is not entirely novel. As was noted in the introduction, Klein (2000; see also Tipper et al., 1997) proposed a similar dual-process account to explain the time course of exogenous spatial-cuing effects. According to this account, the exogenous cue leads to a shift in attention toward its location, which results in fast responses to targets that appear at the same location as the cue. However, at the same time, a second process may impede performance on cued trials either by inhibiting attention from returning to the cued location (Reuter-Lorenz, Jha, \& Rosenquist, 1996) or by inhibiting responses to targets at cued locations (Klein \& Taylor, 1994). The overall cuing effect is presumed to reflect the relative contributions to performance of these two opposing processes. By this view, the facilitation effect at short cue-target SOAs occurs because the benefit to performance caused by the target appearing at the attended location is larger than the cost to performance caused by some other process that slows processing of targets at cued locations. With longer SOAs, it is assumed that attention is removed from the cued location, reducing the benefit for cued trials and, thus, revealing an overall cost for cued trials, relative to uncued trials.

Taken literally, the dual-process account of exogenous spatial-cuing effects put forward by Klein (2000) could not possibly explain the repetition effects reported in the present study, since the two processes in Klein's (2000) account are related specifically to shifts of visual attention in space. Nonetheless, the spirit of Klein's (2000) dual-process account is similar to that offered here. In the following sections, we describe more specifically the types of processes that might fit our dual-process framework. Although, at this point, we have no way to evaluate such a possibility, we have opted for process descriptions that are sufficiently broad that they might encompass those offered to explain exogenous spatial-cuing effects.

\section{Episodic integration}

Some of the earliest research on repetition effects attributed the faster performance to repeated targets to an automatic priming process triggered by presentation and response to the first of two targets (Kirby, 1976; Kornblum, 1973). Subsequent research that focused specifically on whether the repetition benefit owed to stimulus repetition or response repetition (e.g., Bertelson, 1965; Smith, 1968) eventually gave way to the view that $\mathrm{S}-\mathrm{R}$ bindings play an important role (Hommel, 1998; Pashler \& Baylis, 1991; Rabbitt, 1968). According to this view, response to repeated targets is particularly fast because these targets automatically cue the retrieval of the $\mathrm{S}-\mathrm{R}$ binding from the immediately preceding trial and use of this $\mathrm{S}-\mathrm{R}$ binding offers a savings to performance, relative to the more analytic process of assigning a response based on the task-defined S-R rule (see also 
Logan, 1988). Following these ideas, we have proposed that one of the processes contributing to performance in our tasks involves integration of T1 and T2 S-R episodes. By this view, responses to repeated $\mathrm{T} 2$ targets are typically fast because of the benefit associated with retrieving an S-R episode for a similarly encoded and responded-to T1 (Hommel, 1998; Kahneman et al., 1992; Logan, 1988).

We have assumed further that the requirement to respond to an intervening event disrupts this episodic integration process and that, in the absence of the benefit afforded by episodic integration, we can measure the influence of a separate process that slows performance for repeated, relative to not-repeated, trials. However, it is worth considering whether episodic integration itself might lead to slower performance for repeated, relative to not-repeated, trials under conditions in which participants respond to an intervening event. Note that if episodic integration itself could produce repetition costs, there would be no need for a dualprocess account; episodic integration would explain both repetition benefits and repetition costs.

One way in which episodic integration processes could produce repetition costs stems from the idea that onset of $\mathrm{T} 2$ could cue the retrieval of a T1-processing episode that is inappropriate for transfer to T2 (see Hommel, 1998, for an application of this idea to performance in 2AFC tasks; for applications of this idea to studies of negative priming, see Neill \& Mathis, 1998; Wood \& Milliken, 1998). According to this view, this inappropriate transfer effect occurs when there is a "partial match" between the T1- and T2processing episodes. In the case of a partial match, some additional processing may be required prior to response, processing dedicated to resolving discrepancies between the current target and associated task requirements, on the one hand, and the retrieved S-R episode, on the other hand.

To apply this idea to the results of our experiments, one might assume that processing of the intervening event would be bound to the processing episode of $\mathrm{T} 1$, which would then be retrieved when $\mathrm{T} 2$ is identical to $\mathrm{T} 1$. The T1-intervening-event bound episode would then contain relevant processing needed to efficiently process a repeated $\mathrm{T} 2$, but also the irrelevant processing associated with the intervening event. If a repeated target retrieves both relevant and irrelevant processing, some additional time may be required to integrate selectively just the relevant aspects of the retrieved episode into the current processing episode.

In Experiment 3, we examined this issue by manipulating the temporal interval between $\mathrm{T} 1$ and the intervening event from relatively short in duration $(200 \mathrm{~ms})$ to long $(1,800 \mathrm{~ms})$. The rationale was that events occurring relatively close in time would be more likely to be bound together in a single memory representation than events appearing further apart in time. Yet we observed repetition costs that did not differ in magnitude across these conditions, a finding that fails to support our particular test of an episodic integration account of the repetition costs. In the absence of evidence favoring an episodic integration account of repetition costs, we are left to consider an account in which episodic integration processes are disrupted by the requirement to respond to an intervening event, and the repetition costs measured under these conditions reflect the contribution of some other process. We turn now to the nature of this other process.

\section{Nonspatial inhibition of return}

As was mentioned in the introduction, there have been a handful of studies that have examined whether the process that causes spatial IOR effects might cause analogous effects in studies with nonspatial stimuli (Fox \& de Fockert, 2001; Francis \& Milliken, 2003; Kwak \& Egeth, 1992; Law et al., 1995; Taylor \& Klein, 1998a). Differences in empirical properties can indeed be observed across studies of spatial and nonspatial orienting (e.g., Kwak \& Egeth, 1992; Taylor \& Klein, 1998a), which has led some researchers to conclude that the process responsible for spatial IOR effects does not contribute to performance in studies of nonspatial orienting. Yet we have pointed out here that such inferences often depend on an assumption that empirical effects are pure measures of a single process. If this assumption is incorrect, qualitatively different spatial and nonspatial repetition effects may occur when at least one common underlying process is involved.

This possibility was examined here with specific reference to performance in tasks that require a response to targets on consecutive trials (i.e., a target-target procedure). Prior research has shown that target-target spatial repetition procedures commonly lead to IOR effects (e.g., Kwak \& Egeth, 1992; Maylor \& Hockey, 1985), whereas targettarget nonspatial repetition procedures commonly lead to repetition priming effects (e.g., Bertelson, 1961; Kwak \& Egeth, 1992; Tanaka \& Shimojo, 1996; Taylor \& Donnelly, 2002). Indeed, nonspatial IOR-like effects have been reported to date solely with procedures in which a response is withheld to a first event and then made to a second event (i.e., a cue-target procedure; see Fox \& de Fockert, 2001; Francis \& Milliken, 2003; Law et al., 1995), and not when a response is required to both of two consecutive events (i.e., a target-target procedure) The IOR-like effects observed with a target-target procedure in the present study are, therefore, novel and are important because they rule out the idea that all nonspatial IOR-like effects are a byproduct of response inhibition processes that are independent of a "true" IOR process (Welsh \& Pratt, 2006).

These different effects across spatial and nonspatial procedures might lead one to conclude that different processes underlie these effects. Yet, in the present study, the mere requirement to respond to an intervening event between 
nonspatial targets revealed effects that are similar in direction to spatial IOR effects. Of course, the presence of effects that are similar in direction across spatial and nonspatial procedures does not imply that similar mechanisms cause these effects, but these results do highlight that the similarmechanism hypothesis cannot be ruled out.

One might reasonably ask why our intervening-event procedure was required to observe repetition costs here when no such procedure is required to observe spatial IOR effects in 2AFC target localization tasks (Maylor \& Hockey, 1985). One interpretation of this discrepancy is that fundamentally different processes underlie the repetition costs observed in spatial and nonspatial 2AFC tasks. However, an alternative interpretation is that spatial and nonspatial 2AFC tasks differ not in terms of the process that causes repetition costs, but in terms of the process that causes repetition benefits. If repetition benefits in $2 \mathrm{AFC}$ tasks are driven primarily by the retrieval of prior $\mathrm{S}-\mathrm{R}$ episodes, it may be that this episodic integration process plays a much larger role in nonspatial tasks than in spatial tasks. If retrieval of a prior S-R episode affords a much larger benefit in nonspatial $2 \mathrm{AFC}$ tasks than in spatial $2 \mathrm{AFC}$ tasks, it stands to reason that disrupting this process may be much more important in nonspatial tasks than in spatial tasks to observe the presence of an opposing process in performance.

To be clear, we acknowledge that the present data do not require the conclusion that spatial IOR effects and nonspatial repetition costs are caused by the same mechanism. At the same time, the present data do invite consideration of whether spatial IOR effects need be attributed to processes dedicated specifically to controlling the orienting of attention in space. In particular, it is worth asking whether a broader orienting principle that favors processing of novel, relative to familiar, perceptual events would constitute a parsimonious alternative. In line with this possibility, Dukewich (2009) has recently argued against a dedicated spatial-orienting process account of the IOR effect, instead proposing that IOR is caused by habituation of the orienting response.

Support for this broader view may also be found in studies on masked response priming. In these studies, a prime stimulus (e.g., an arrow pointing right) is presented briefly and masked and then is followed by a compatible (i.e., an arrow pointing right) or incompatible (i.e., an arrow pointing left) target (Eimer \& Schlaghecken, 2003). When the temporal interval between prime and target is very brief (e.g., less than $100 \mathrm{~ms}$ ), responses are typically faster for compatible than for incompatible targets. In contrast, when the temporal interval between prime and target is longer, responses are slower for compatible than for incompatible targets (Eimer \& Schlaghecken, 2003; see also Sumner, 2007). An interpretation of this result that fits broadly with our dual-process framework is that responses for the short prime-target SOAs are driven predominantly by integration of activation from the prime and target within the same event representation, leading to facilitation effects. In contrast, for longer prime-target SOAs, performance may not benefit from this episodic integration process, leaving performance to be affected predominantly by an opposing inhibition process (see also Bodner \& Masson, 2001, for a discussion of episodic influences in masked priming).

In summary, a dual-process framework in which episodic integration processes are responsible for repetition benefits and in which a broad orienting principle that favors perceptual processing of novel over familiar events is responsible for repetition costs fits well with the results reported here (see also Dukewich, 2009; Eimer \& Schlaghecken, 2003; $\mathrm{Hu}$, Samuel, \& Chan, 2011). Yet there are other candidate processes that explain repetition costs that could as easily fit within a dual-process framework and that merit some consideration here. We turn now to a discussion of two such candidate processes.

\section{Expectation for alternation}

Kirby (1976) noted that participants respond faster to alternations than to repetitions when the RSI between trials in a 2AFC task is relatively long. To explain this result, Kirby proposed that an expectation favoring alternation builds across time between trials, such that for long RSI trials, this expectation has a stronger influence on performance than does an automatic process that speeds performance for repeated, relative to not-repeated, trials. The issue that merits consideration here is whether expectation for alternation might explain the repetition costs observed in the present study. In other words, could the requirement to respond to an intervening event somehow induce an expectation for alternation rather than repetition? Although this account cannot be ruled out, without some additional evidence it seems somewhat circular. In particular, if any condition that produces repetition costs is interpreted as increasing expectation for alternation, it becomes hard to distinguish between the effect and the mechanism that causes the effect. Some deliberate manipulation of expectation, or measure of expectation separate from the repetition effect itself, might be used to evaluate this idea further in subsequent research.

\section{Backward inhibition}

If not expectation for alternation, the repetition costs observed might be argued to reflect a form of backward inhibition effect (Mayr \& Keele, 2000). The backward inhibition effect is reflected in particularly slow performance when participants are required to shift back to a task that has been performed recently, relative to when they shift to a task that was not performed recently. In effect, performance in task $\mathrm{A}$ is more efficient in the task series CBA than 
in the task series ABA. To demonstrate the backward inhibition effect, Mayr and Keele assigned multiplication questions as task A, addition questions as task B, and subtraction questions as task C. Participants first completed either a block of task A trials or a block of task $\mathrm{C}$ trials. Then they completed a block of task B trials, followed by a block of Task A trials. Performance was slower in the third block when participants had performed the same task in the first block than when they had performed a different task in the first block. Mayr and Keele coined the term backward inhibition to describe this effect, with the idea that switching from task A to task B requires inhibition of the representation of task $\mathrm{A}$, which then makes that representation difficult to access when participants shift back to that task.

To explain our results by reference to a similar backward inhibition process, we would have to assume that responding to the intervening event results in inhibition of taskrelated representations associated with T1. However, slower responses to repeated items in our study cannot simply be explained by reference to inhibition of the color identification task set, since both repeated and not-repeated T2 trials require color identification. Without some additional assumption, inhibition of the T1 task representation would result in long RTs for both repeated and not-repeated T2 trials. To salvage a backward inhibition account, one might propose that task representations are bound to stimuli to which they are applied, in which case inhibition is directed at a representation of the color identification task that is bound to a particular colored T1. In this case, inhibition might be expected to slow performance only if T2 cues the retrieval of this particular representation - that is, when T2 matches the color of T1. This episodic variant of the backward inhibition hypothesis merits consideration.

At the same time, there are aspects of our results that are difficult to reconcile with a backward inhibition account. For instance, if response to the intervening event in our task requires a shift in task set that triggers inhibition of the prior task representation, responses to $\mathrm{T} 2$ should have been slower in the intervening-event condition than in the no-interveningevent condition. Yet there was no evidence in any of our experiments for such an effect. In fact, in Experiments 1A and 4, the opposite pattern was observed; that is, participants responded faster to $\mathrm{T} 2$ in the intervening-event condition than in the no-intervening-event condition. Nonetheless, given the face similarity between the procedure used here and those used to measure the backward inhibition effect in task switching, additional research on this issue seems warranted.

\section{Conclusion}

We propose that repetition effects in $2 \mathrm{AFC}$ tasks may be caused by two separate and opposing processes. This proposal is supported by the finding that the customary repetition benefit reverses to a repetition cost when participants are required to respond to an intervening event between consecutive targets. This effect was observed for a range of different target stimuli, intervening-event stimuli, and modes of responding to the intervening event. Although it is unclear how best to describe the processes themselves, a compelling possibility is that the repetition costs observed here constitute a nonspatial variant of the IOR effect. According to this view, response to the intervening event disrupts an episodic integration process that is the basis of the repetition benefit commonly observed in such tasks. In the absence of this episodic integration process, a repetition cost in performance is revealed, perhaps caused by a habituation process that can be observed with both spatial and nonspatial orienting methods (Dukewich, 2009).

Author Note This research was supported by an NSERC Discovery grant to B.M. We thank Ellen MacLellan for programming help.

\section{References}

Bertelson, P. (1961). Sequential redundancy and speed in a serial twochoice responding task. Quarterly Journal of Experimental Psychology, 13, 90-102.

Bertelson, P. (1965). Serial choice reaction-time as a function of response versus signal-and-response repetition. Nature, 206, 217-218.

Bertelson, P. (1967). The time course of preparation. Quarterly Journal of Experimental Psychology, 19, 272-279.

Bodner, G. E., \& Masson, M. E. J. (2001). Prime validity affects masked repetition priming: Evidence from an episodic resource account of priming. Journal of Memory and Language, 45, 616-647.

Campana, G., \& Casco, C. (2009). Repetition effects of features and spatial position: Evidence for dissociable mechanisms. Spatial Vision, 22, 325-338.

Chica, A. B., Klein, R. M., Rafal, R. D., \& Hopfinger, J. B. (2010). Endogenous saccade preparation does not produce inhibition of return: Failure to replicate Rafal, Calabresi, Brennan, \& Sciolto (1989). Journal of Experimental Psychology: Human Perception and Performance, 36, 1193-1206.

Dukewich, K. R. (2009). Reconceptualizing inhibition of return as habituation of the orienting response. Psychonomic Bulletin \& Review, 16, 238-251.

Eimer, M., \& Schlaghecken, F. (2003). Response facilitation and inhibition in subliminal priming. Biological Psychology, 64, 726.

Fox, E., \& de Fockert, J. W. (2001). Inhibitory effects of repeating color and shape: Inhibition of return or repetition blindness? Journal of Experimental Psychology: Human Perception and Performance, 27, 798-812.

Francis, L., \& Milliken, B. (2003). Inhibition of return for the length of a line? Perception \& Psychophysics, 65, 1208-1221.

Hillstrom, A. P. (2000). Repetition effects in visual search. Attention, Perception, \& Psychophysics, 62, 800-817.

Hommel, B. (1998). Event files: Evidence for automatic integration of stimulus response episodes. Visual Cognition, 5, 183-216.

Hu, F. K., Samuel, A. G., \& Chan, A. S. (2011). Eliminating inhibition of return by changing salient nonspatial attributes in a complex 
environment. Journal of Experimental Psychology: General, 140, $35-50$.

Huang, L., Holcomb, A. O., \& Pashler, H. (2004). Repetition priming in visual search: Episodic retrieval, not feature priming. Memory \& Cognition, 32, 12-20.

Jacoby, L. (1991). A process dissociation framework: Separating automatic from intentional uses of memory. Journal of Memory and Language, 30, 513-541.

Kahneman, D., Triesman, A., \& Gibbs, B. J. (1992). The reviewing of object files: Object-specific integration of information. Cognitive Psychology, 24, 175-219.

Kirby, N. H. (1976). Sequential effects in two-choice reaction time: Automatic facilitation or subjective expectancy? Journal of Experimental Psychology: Human Perception and Performance, 2, 567-577.

Klein, R. M. (1988). Inhibitory tagging system facilitates visual search. Nature, 334, 430-431.

Klein, R. M. (2000). Inhibition of return. Trends in Cognitive Sciences, 4, 138-147.

Klein, R. M., \& Taylor, T. L. (1994). Categories of cognitive inhibition, with reference to attention. In D. Dagenbach \& T. H. Carr (Eds.), Inhibitory processing in attention, memory, and language (pp. 113-150). San Diego: Academic.

Kornblum, S. (1973). Sequential effects in choice reaction time: A tutorial review. In S. Kornblum (Ed.), Attention and performance IV (pp. 259-288). New York: Academic.

Kristjánsson, A., \& Campana, G. (2010). Where perception meets memory: A review of repetition priming in visual search tasks. Attention, Perception, \& Psychophysics, 72, 5-18.

Kwak, H. W., \& Egeth, H. (1992). Consequences of allocating attention to locations and to other attributes. Perception \& Psychophysics, 51, 455-464.

Law, M. B., Pratt, J., \& Abrams, R. A. (1995). Color-based inhibition of return. Perception \& Psychophysics, 57, 402-408.

Logan, G. D. (1988). Towards an instance theory of automatization. Psychological Review, 95, 492-527.

Logan, G. D. (1990). Repetition priming and automaticity: Common underlying mechanisms? Cognitive Psychology, 22, 1-35.

Lupiáñez, J., Klein, R. M., \& Bartolomeo, P. (2006). Inhibition of return: Twenty years after. Cognitive Neuropsychology, 23, 1003-1014.

Lupiáñez, J., Milán, E. J., Tornay, F. J., Madrid, E., \& Tudela, P. (1997). Does IOR occur in discrimination tasks? yes, it does, but later. Attention, Perception, \& Psychophysics, 59, 1241-1254.

Maljkovic, V., \& Nakayama, K. (1994). Priming of pop-out: I. Role of features. Memory \& Cognition, 22, 657-672.

Maylor, E. A., \& Hockey, R. (1985). Inhibitory control of externally controlled overt orienting in visual space. Journal of Experimental Psychology: Human Perception and Performance, 11, 777-787.

Mayr, U., \& Keele, S. W. (2000). Changing the internal constraints on action: The role of backward inhibition. Journal of Experimental Psychology: General, 129, 4-26.

Milliken, B., Joordens, S., Merikle, P. M., \& Seiffert, A. E. (1998). Selective attention: A reevaluation of the implications of negative priming. Psychological Review, 105, 203-229.

Neill, W. T., \& Mathis, K. M. (1998). Transfer-inappropriate processing: Negative priming and related phenomena. In D. L. Medin
(Ed.), The psychology of learning and motivation: Advances in research and theory (Vol. 38, pp. 1-44). San Diego: Academic.

Pashler, H., \& Baylis, G. C. (1991). Procedural learning: 2. Intertrial repetition effects in speeded-choice tasks. Journal of Experimental Psychology: Learning, Memory, and Cognition, $17,33-48$.

Posner, M. I. (1980). Orienting of attention. Quarterly Journal of Experimental Psychology, 32, 3-25.

Posner, M. I., \& Cohen, Y. (1984). Components of visual orienting. In H. Bouma \& D. G. Bouwhuis (Eds.), Attention and performance $X$ (pp. 531-556). Hillsdale: Erlbaum.

Rabbitt, P. M. A. (1968). Repetition effects and signal classification strategies in serial choice-response tasks. Quarterly Journal of Experimental Psychology, 20, 232-240.

Rafal, R. D., Calabresi, P. A., Brennan, C. W., \& Sciolto, T. K. (1989). Saccade preparation inhibits re-orienting to recently attended locations. Journal of Experimental Psychology: Human Perception and Performance, 15, 673-685.

Reuter-Lorenz, P. A., Jha, A. P., \& Rosenquist, J. N. (1996). What is inhibited in inhibition of return? Journal of Experimental Psychology: Human Perception and Performance, 22, 367-378.

Samuel, A. G., \& Kat, D. (2003). Inhibition of return: A graphical meta-analysis of its time course and an empirical test of its temporal and spatial properties. Psychonomic Bulletin \& Review, 10, 897-906.

Smith, M. C. (1968). Repetition effect and short-term memory. Journal of Experimental Psychology, 77, 435-439.

Sumner, P. (2007). Negative and positive masked-priming-implications for motor inhibition. Advances in Cognitive Psychology, 3, 317-326.

Tanaka, Y., \& Shimojo, S. (1996). Location vs feature: Reaction time reveals dissociation between two visual functions. Vision Research, $36,2125-2140$.

Taylor, T. L., \& Donnelly, M. P. W. (2002). Inhibition of return for target discriminations: The effect of repeating discriminated and irrelevant stimulus dimensions. Perception \& Psychophysics, 64, 292-317.

Taylor, T. L., \& Klein, R. M. (1998a). Inhibition of return to color: A replication and nonextension of Law, Pratt, and Abrams (1995). Perception \& Psychophysics, 60, 1452-1455. discussion 14551456.

Taylor, T. L., \& Klein, R. M. (1998b). On the causes and effects of inhibition of return. Psychonomic Bulletin \& Review, 5, 625-643.

Tipper, S. P., Rafal, R., Reuter-Lorenz, P. A., Starrveldt, Y., Ro, T., Egly, R., \& Weaver, B. (1997). Object-based facilitation and inhibition from visual orienting in the human split-brain. Journal of Experimental Psychology. Human Perception and Performance, 23, $1522-1532$.

Van Selst, M., \& Jolicoeur, P. (1994). A solution to the effect of sample size on outlier elimination. Quarterly Journal of Experimental Psychology, 47A, 631-650.

Welsh, T. N., \& Pratt, J. (2006). Inhibition of return in cue-target and target-target tasks. Experimental Brain Research, 174, 167-175.

Wood, T. J., \& Milliken, B. (1998). Negative priming without ignoring. Psychonomic Bulletin \& Review, 5, 470-475. 